\title{
Mapping surface rock exposures to enhance geohaza rd susceptibility assessment: a random forest approach
}

Chris Willia ms, Andrew Finla yson, Romesh Pa la makumbura, Tim Kea rsey, Severine Comillon, Sam Roberson and Katie Whitbread

British Geological Survey, UK

Contact: chrwil@bgs.ac.uk 


\section{Overview}

$\square$ Rationale

$\checkmark$ What we want to achieve

$\square$ Real world applications

$\square$ Current data sets and limitations

Methodology
Build ing tra ining da ta sets

- Manual data capture

$\checkmark$ Altemative resources

B Building a model

Data inputs

$\checkmark$ Preliminary results

$\square$ Next steps 


\section{Project rationale}

Knowing where bedrock is exposed in an area is useful information when considering for example geohazards, natural resource mapping, understanding the hydrogeological func tioning of catchments a nd site considerations for eng ineering (Scarpone et al. 2017)

Exposed rock information is sparse in the UK, particularly in upland areas - this is partly related to a lack of boreholes in these areas which have been the key input to past modelling activities

Improving our knowledge for rock exposure, we can improve

$\square$ how we model sediment thic kness

$\square$ how we understand landscape history and wider environmental processes

$\square$ our assessment of geohaza rd susceptibility (e.g. landslides)

$\square$ what information we can incorporate into the geoscience products and dataset that we develop 


\section{What we want to achieve}

A dataset consisting of rock presence or absence for upland regions of the UK

A robust and repeatable process specific catchment modelling workflow

Improved understanding of location specific processes that have resulted in surface rock exposure

- The resultant exposed rock presence/absence will act as an input to modelling efforts foc ussed on constra ining superfic ial sed iment thic kness which underpins the work of the BGS in geohazards whilst also providing a useful data set in its own right to a range of users including:

u Utility sec tor

口 Transport sector

$\square$ Engineering sector 


\section{Methodology}

1. Consider the UK as a series of doma ins that have been subject to common environmental processes

2. For a select number of catchments within each doma in, build up a catalogue of testing and training data:

rock exposure presence/absence datasets

$\checkmark$ geomorphometric parameters (terra in derivatives)

3. Qualify remote observations with field surveys

4. Build a random forest classifier for test sites

$\square$ assess model sensitivity to input variables

$\square$ test model application on inter- and intra-domain sites

5. Apply the resultant model(s) a cross UK upland a reas to create a national upland rock exposure dataset 


\section{(c) (1)}

\section{Common process doma ins}

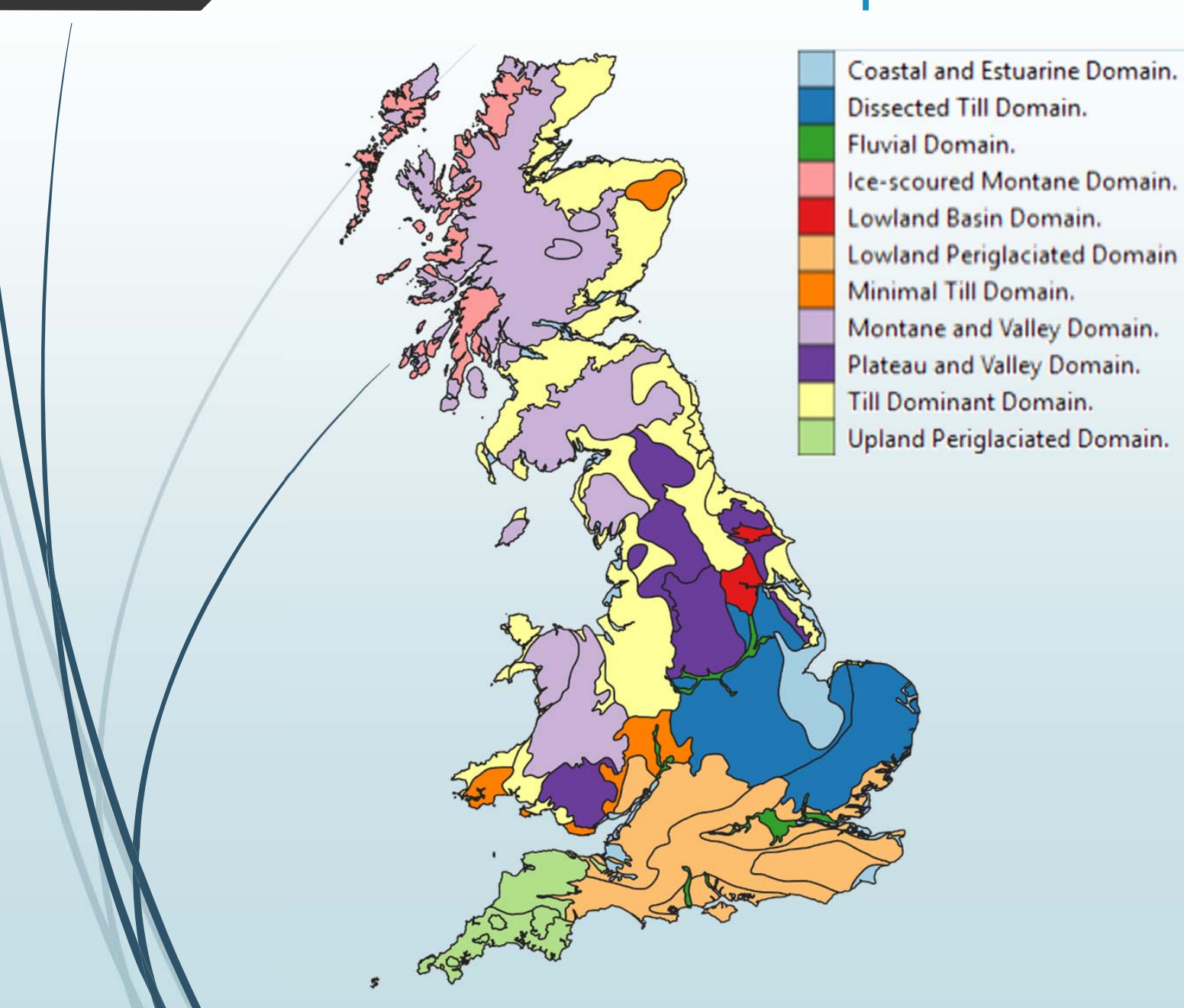

We consider the UK in terms of separate quatemary domains where each domain accounts for a landscape that has been exposed to common processes (see Booth et al., 2015)

$\square$ The designation of these areas is based on the land systems approach developed (Eyles, 1983; Benn and Evans, 1998) 


\section{(c) (1)}

\section{Common process domains}

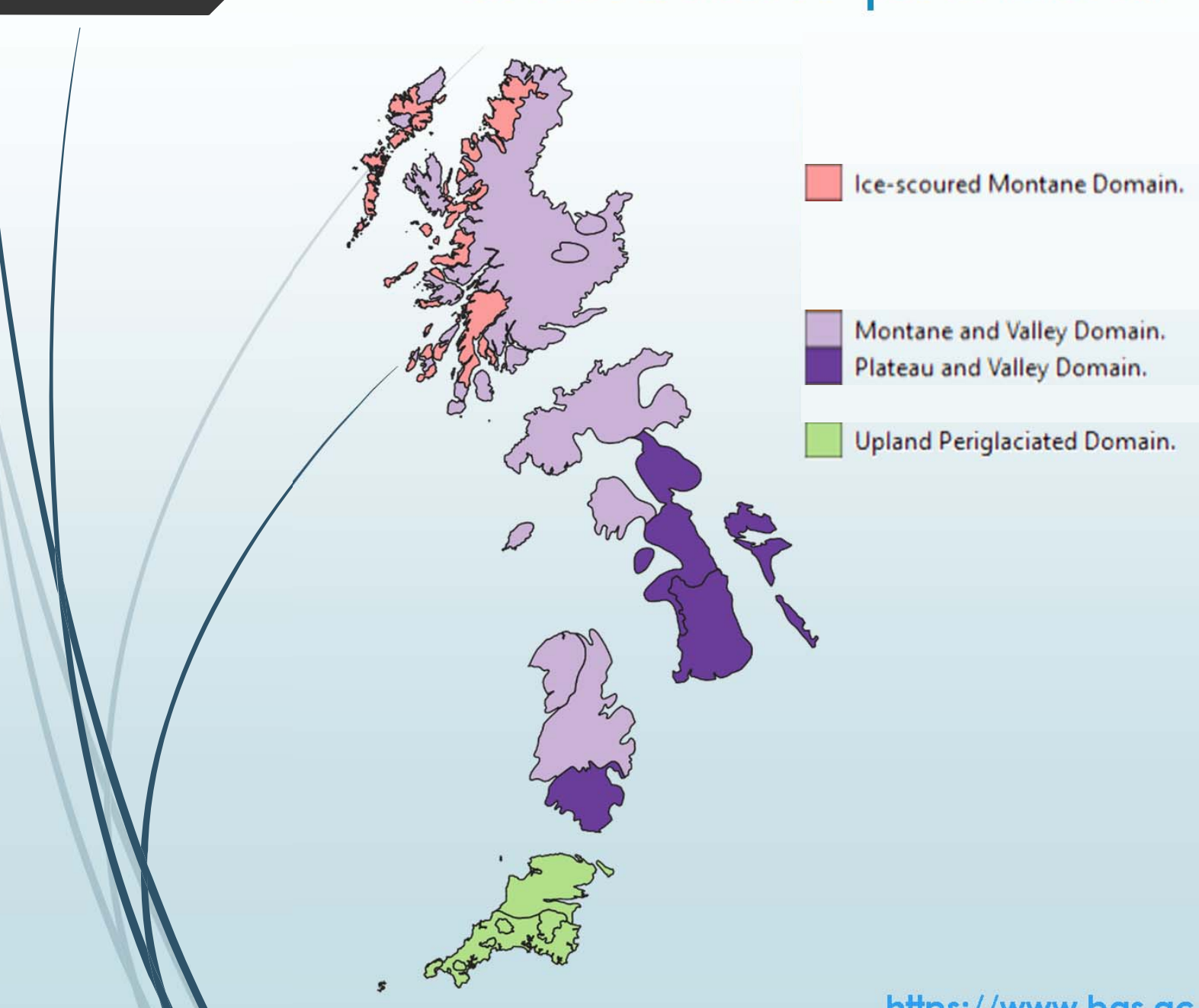

- In this study we a re foc using on those domains in upland areas

- For each of these domains, a number of test catc hments a re selected for which we are developing training/testing data sets for model development 


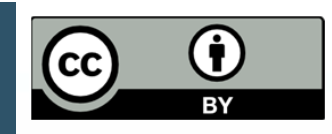

\section{Test site:}

\section{Glengyle, Loch Lomond and Trossachs} National Park, Scotland

Quatemary domain: Montane and Valley

\section{Location:}

Area:

$56.292125^{\circ} \mathrm{N},-4.636513^{\circ} \mathrm{E}$

$11.6 \mathrm{~km}^{2}$

glengyle_catchment.kmz

- The catchment is on the edge of Loch Katrine which is a major reservoir for the city of G lasgow

W Within the catchment, there is a large a mount of power infrastruc ture with an associated access road

- This catchment and the surrounding area has been subject to extensive debris flow ac tivity in recent years

- No mapped rock exposure or sediment thic kness data were available here prior to this study

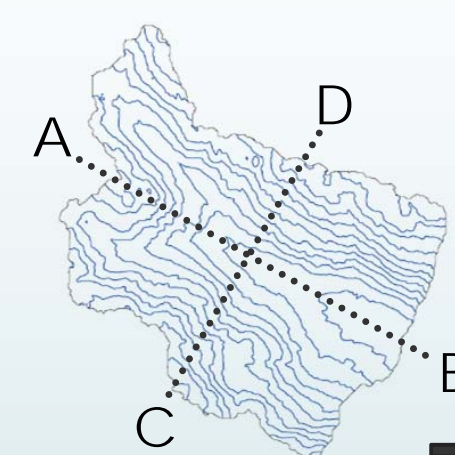

50 metre contour profile

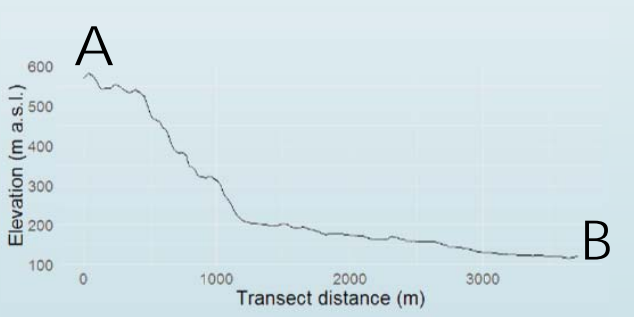

${ }_{500} \mathrm{C}$

D 


\section{(9) (1)}

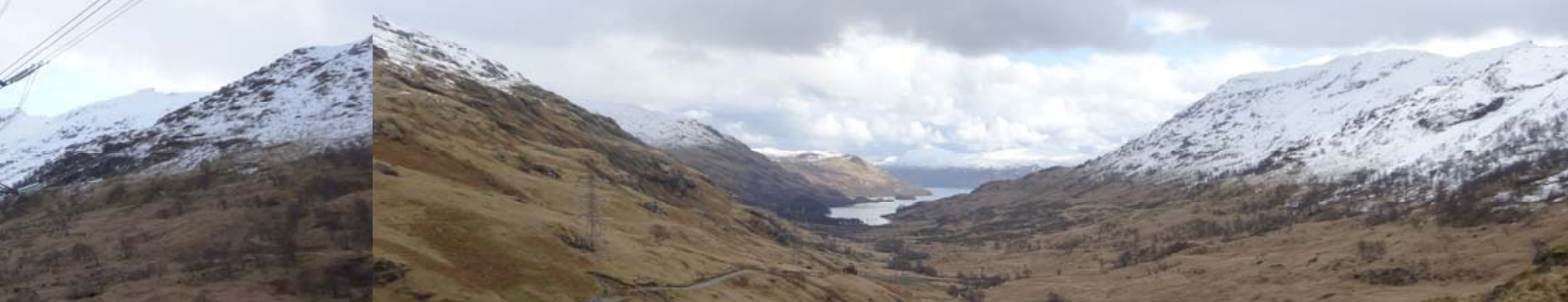

coss $x+2 x^{2}=$
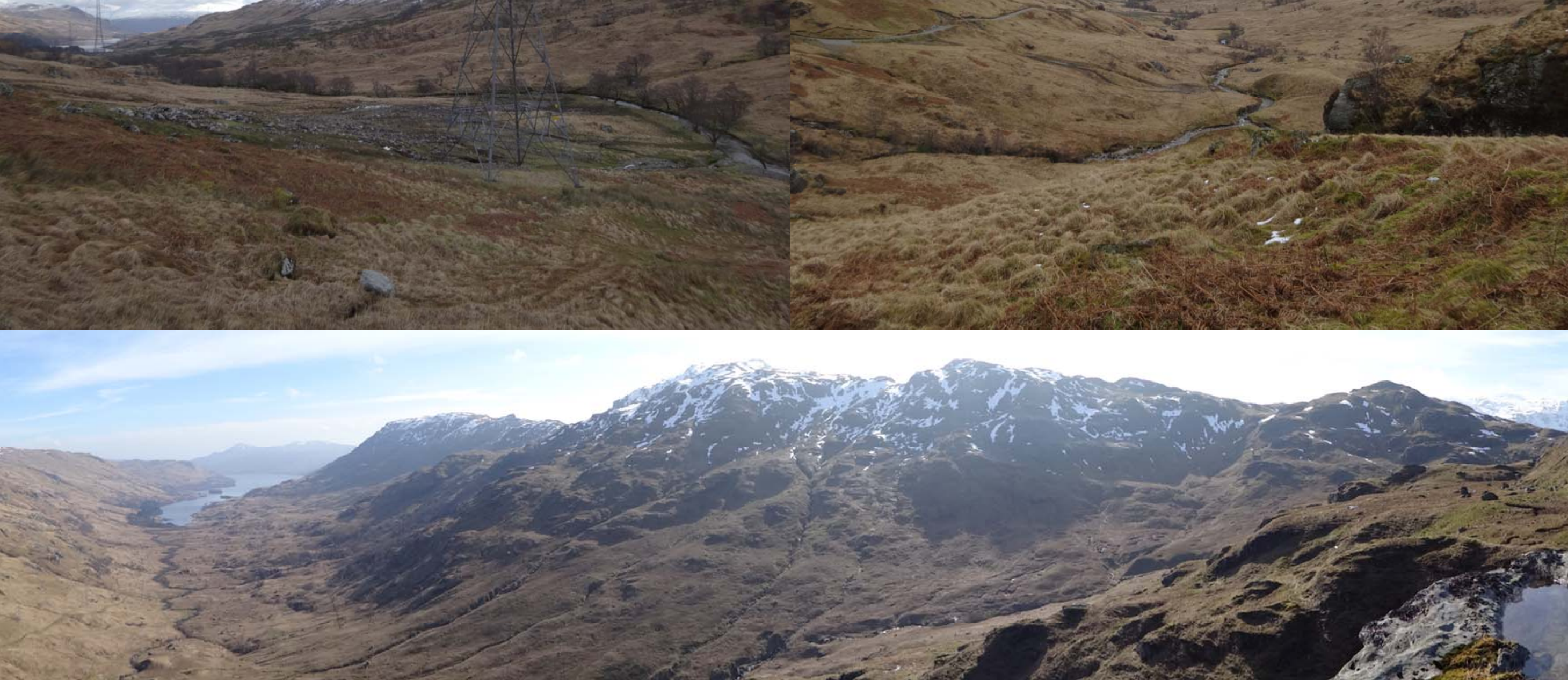


\section{Build ing tra ining datasets}

For each domain, train/test catchment data include:

$\square$ Rock presence and absence from a erial photography

$\square$ these data are created by 4-5 geologists who manual digitize points relative to a $10 \mathrm{~m}$ grid where rock through to be present

- Point data are then rasterised to create $a 1 / 0$ presence/absence raster

$\square$ For some of these catchments, a field

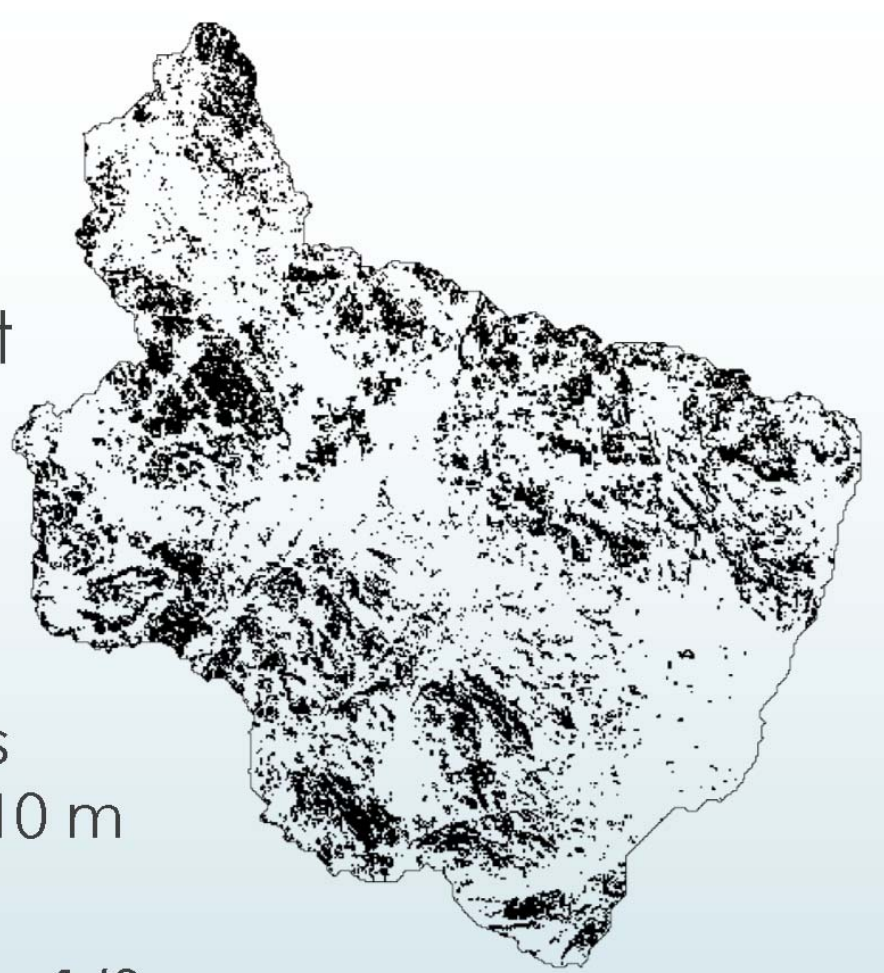
survey is then camied out to validate the digitising approach

Rock present (1) Rock absent (0) 


\section{Build ing training data sets}

$\square$ Terrain derivatives based on a $5 \mathrm{~m}$ resolution digital terra in model:

Slope, aspect, curva ture, topographic position index, multiresolution index of valley bottom and ridge top flatness....

$\square$ Earth observation data

$\square$ RGB a erial photographs $\square$ Sentinel 2 NDVI

$\square$ Mapped geology data sets - Superficial and bedrock
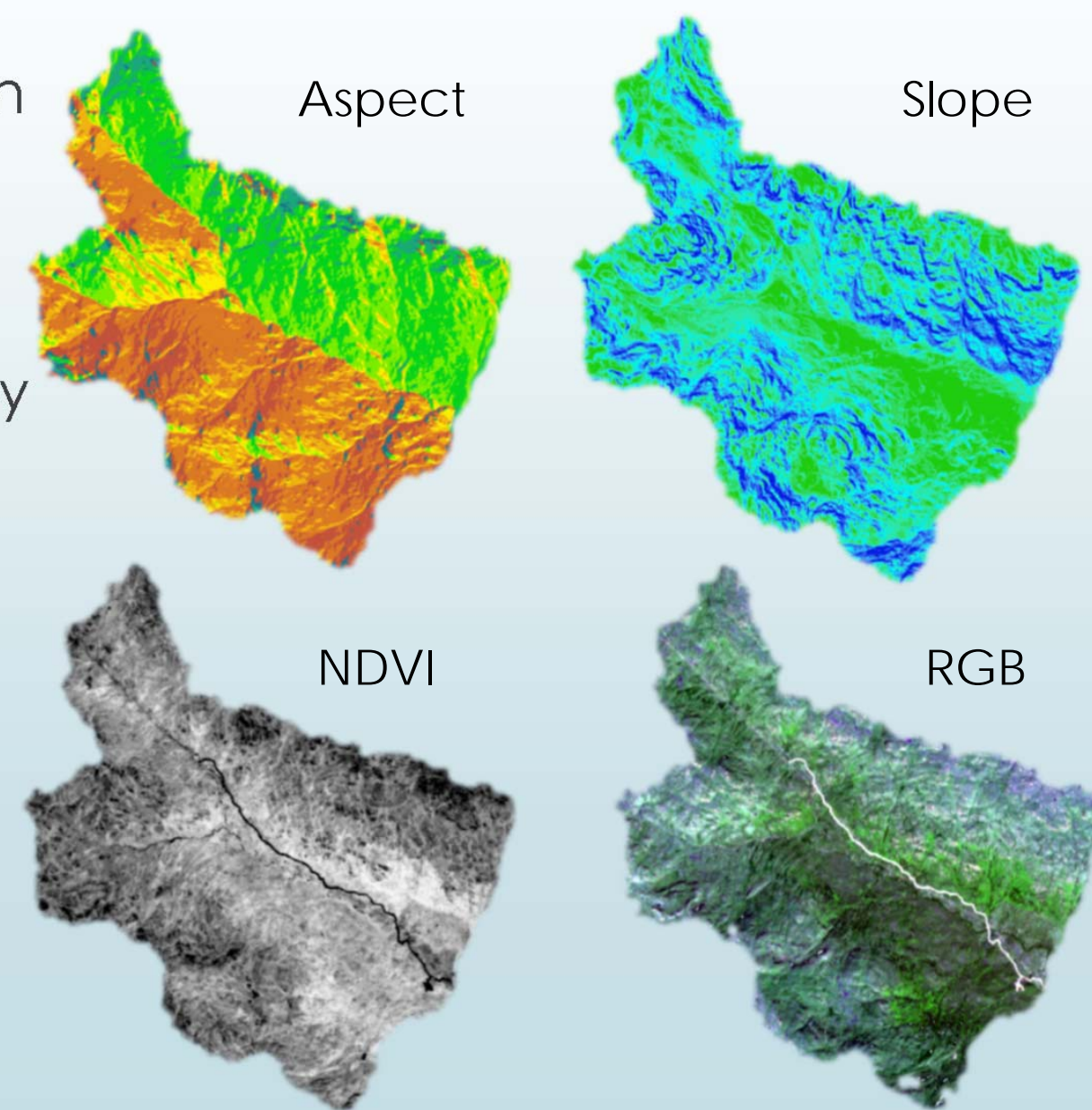

RGB

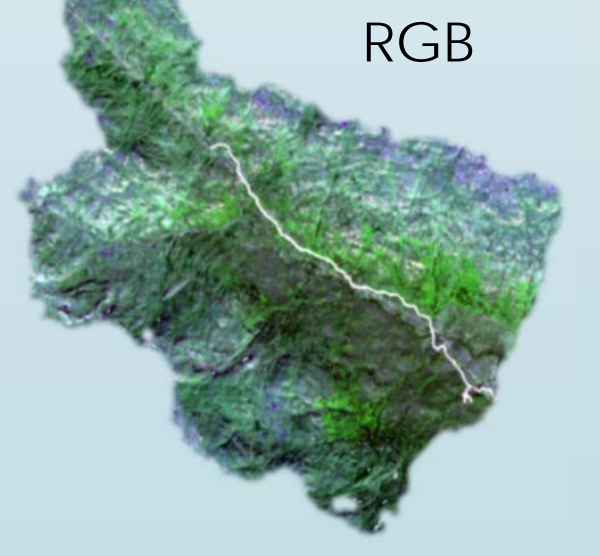




\section{Building the model}

We build a random forest classifier to predict rock exposure presence and absence based on 29 variables (terrain derivatives, EO, bedrock geology...)

- These gridded variables a re first mapped to coordinates a cross the area of interest with a $10 \mathrm{~m}$ spacing

- Categorical data are one-hot encoded

- All data a re scaled between 1 and 0

A train:testsplit of 60:40 is used and then passed to a random forest classifier using the python package scikit leam

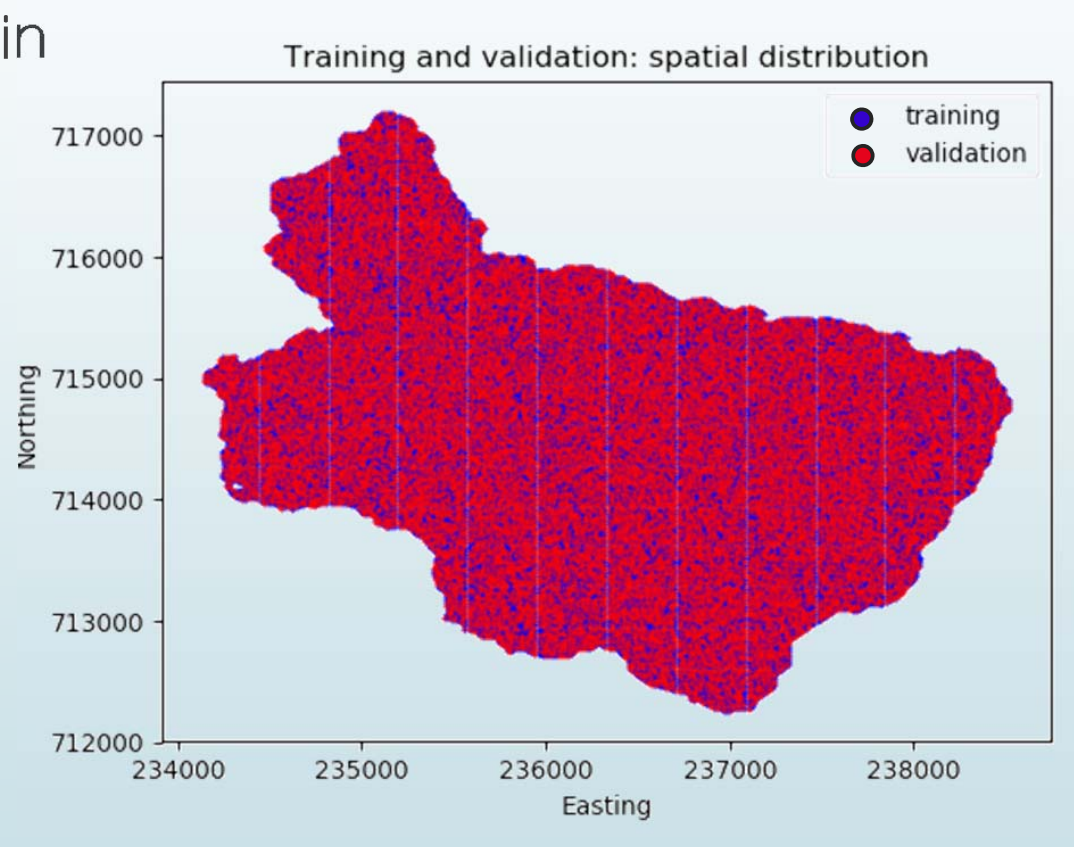

$\square$ Training data rows: 68460

$\square$ Test data rows: $\mathbf{4 5 6 4 0}$ 


\section{Results: c onfusion matrix}

- Initial model based on test:tra in

- Overall accuracy (predicted vs test): $81.4 \%$

a Tendency to under-predict rock presence given the training data*

- Scaling of training variables appears to have little impact on the modelling

With scaling (0-1): $81.6 \%$

Without scaling : $81.5 \%$

- No hyperparameter tuning or model optimisation has been undertaken at this point

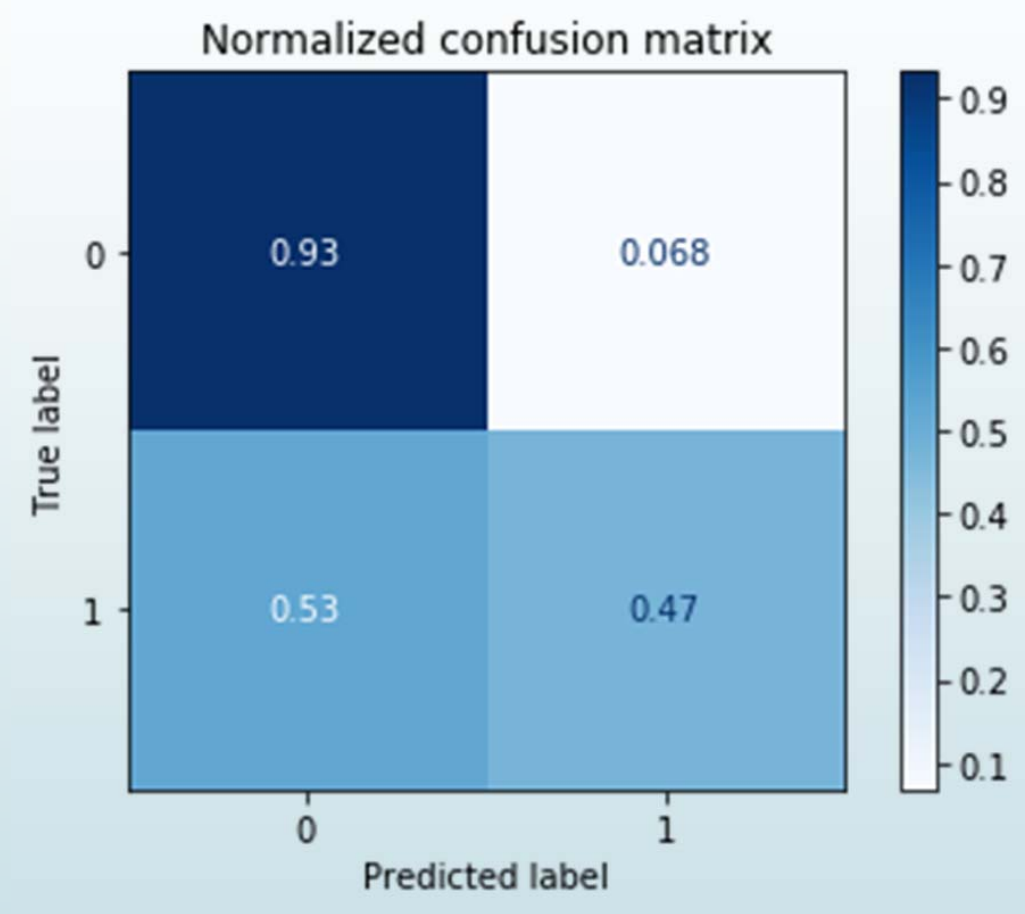

* the training data is based on the interpretation of a human mapper - the "quality" of the training data will be considered in future by companing multiple training sets from differ mappers 


\section{Results}

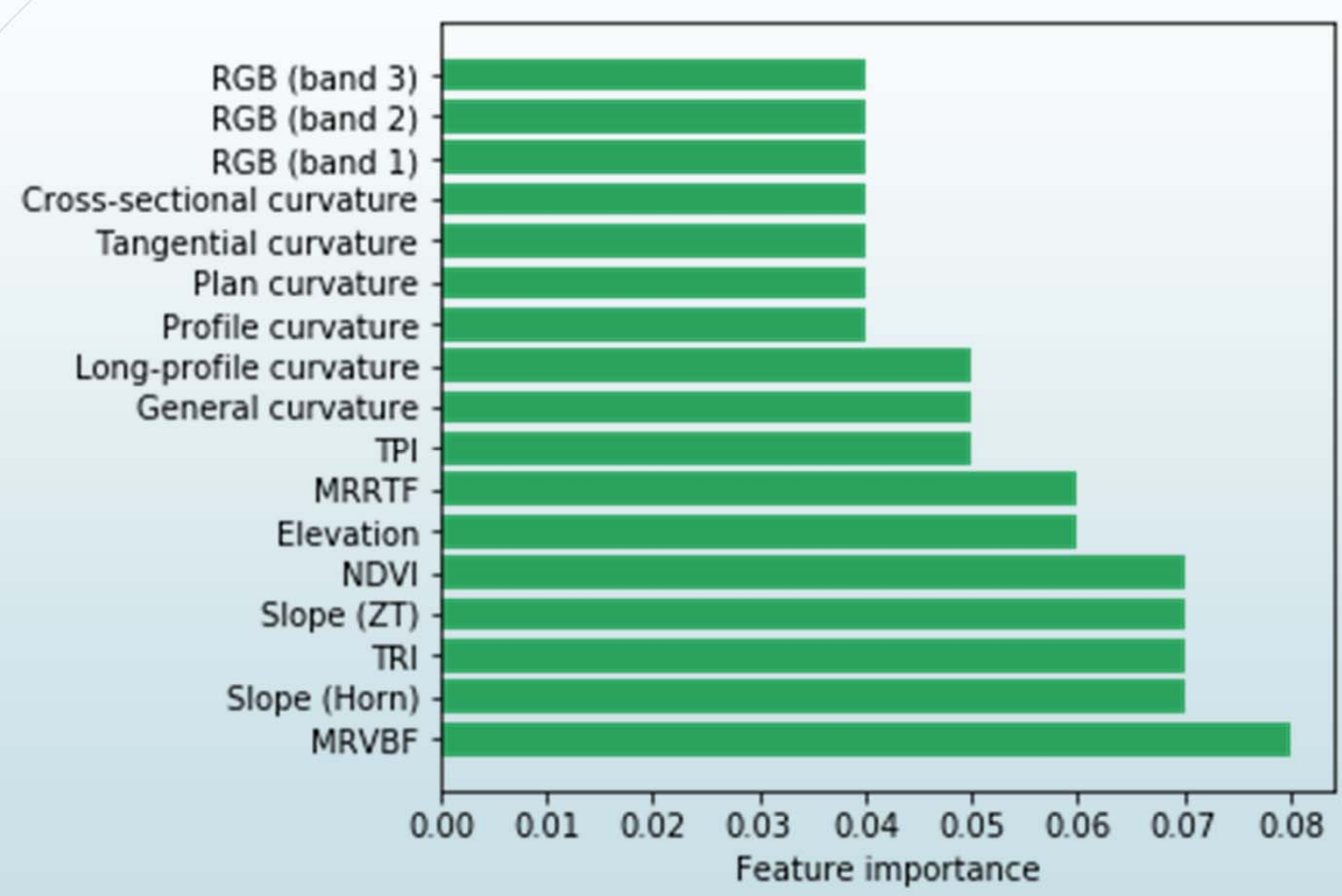

Geology type variables were found to be of minimal importance within the model

The spatial scale underpinning the calculation of variables including MRVBF, MRRTF and TPI may be important and requires further testing

NB/ This is only a selection of the most important variables

MRVBF: Multiresolution index of valley bottom and ridge top flatness MRRIF: Multiresolution index of ridge top flatness TR: Topographic Ridge Index
TPI: Topographic Position Index

Slope (Hom): Slope calc ulated using the Hom method

Slope (ZI): Slope calculated using the Zevenbergen and Thome method 


\section{(c) (1)}

\section{Results: observed vs modelled}
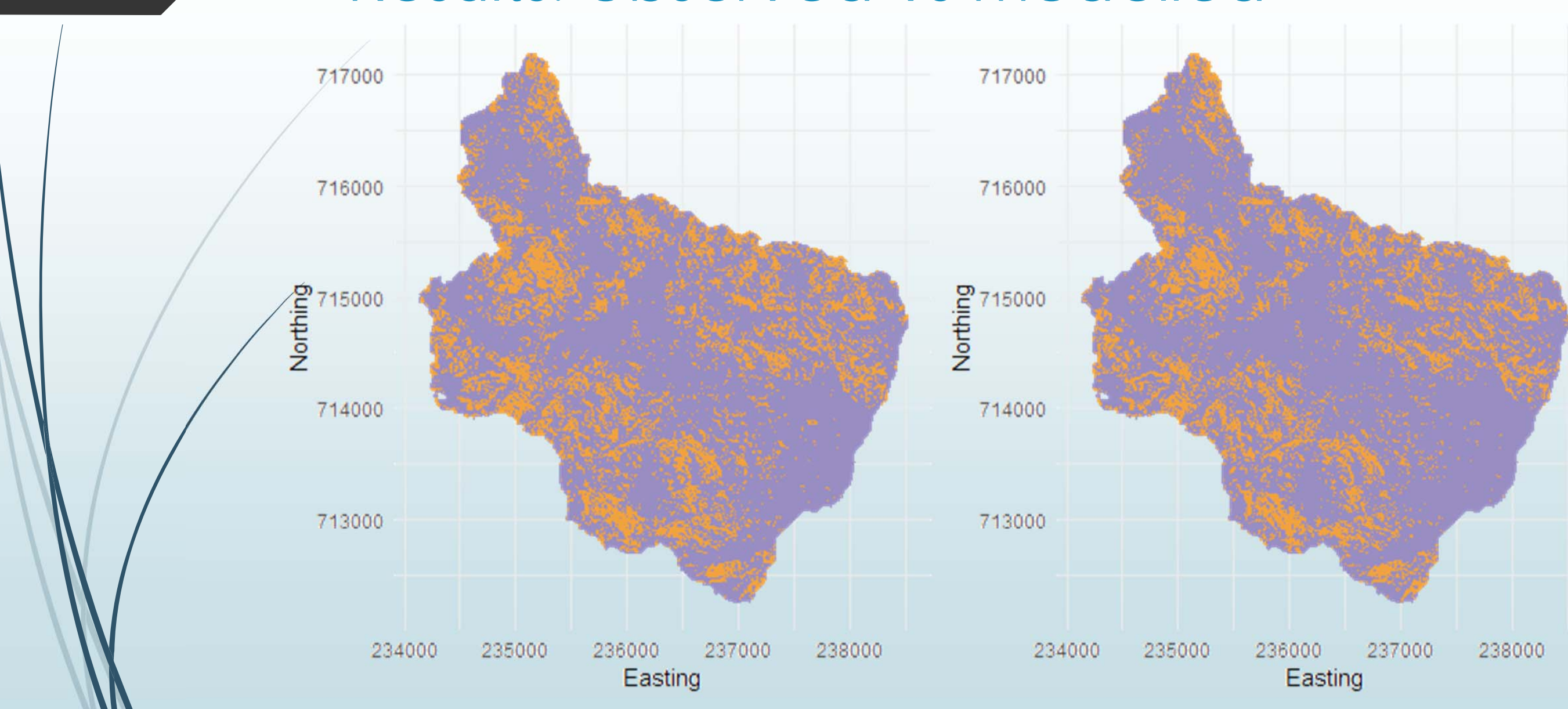

Observed presence/absence

Modelled presence/absence 


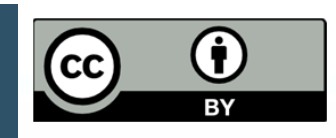

\section{Results: false positives/negatives}
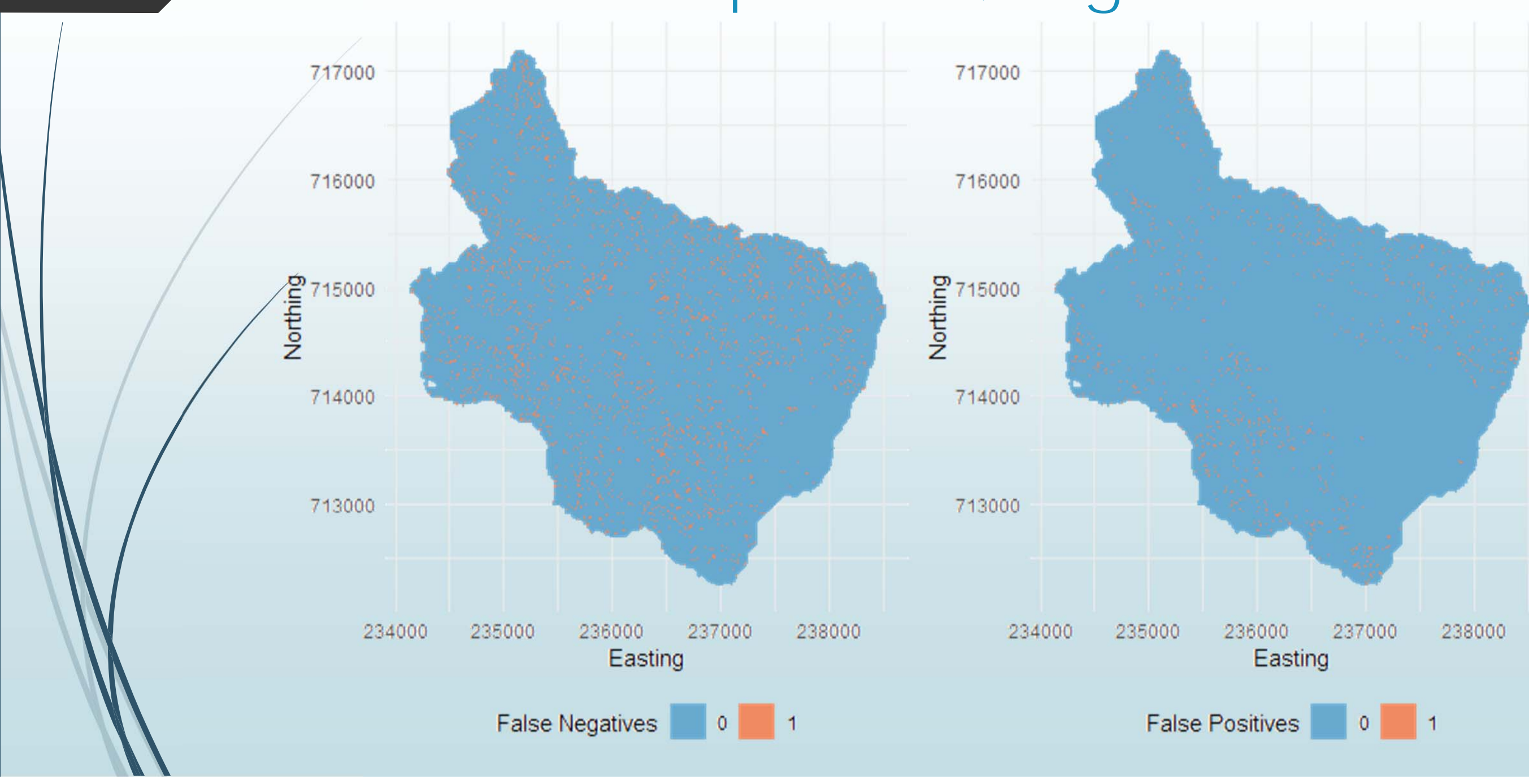

False Negatives

False Positives

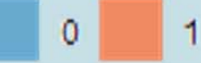




\section{(c) (1)}

\section{Results: true positives/ negatives}
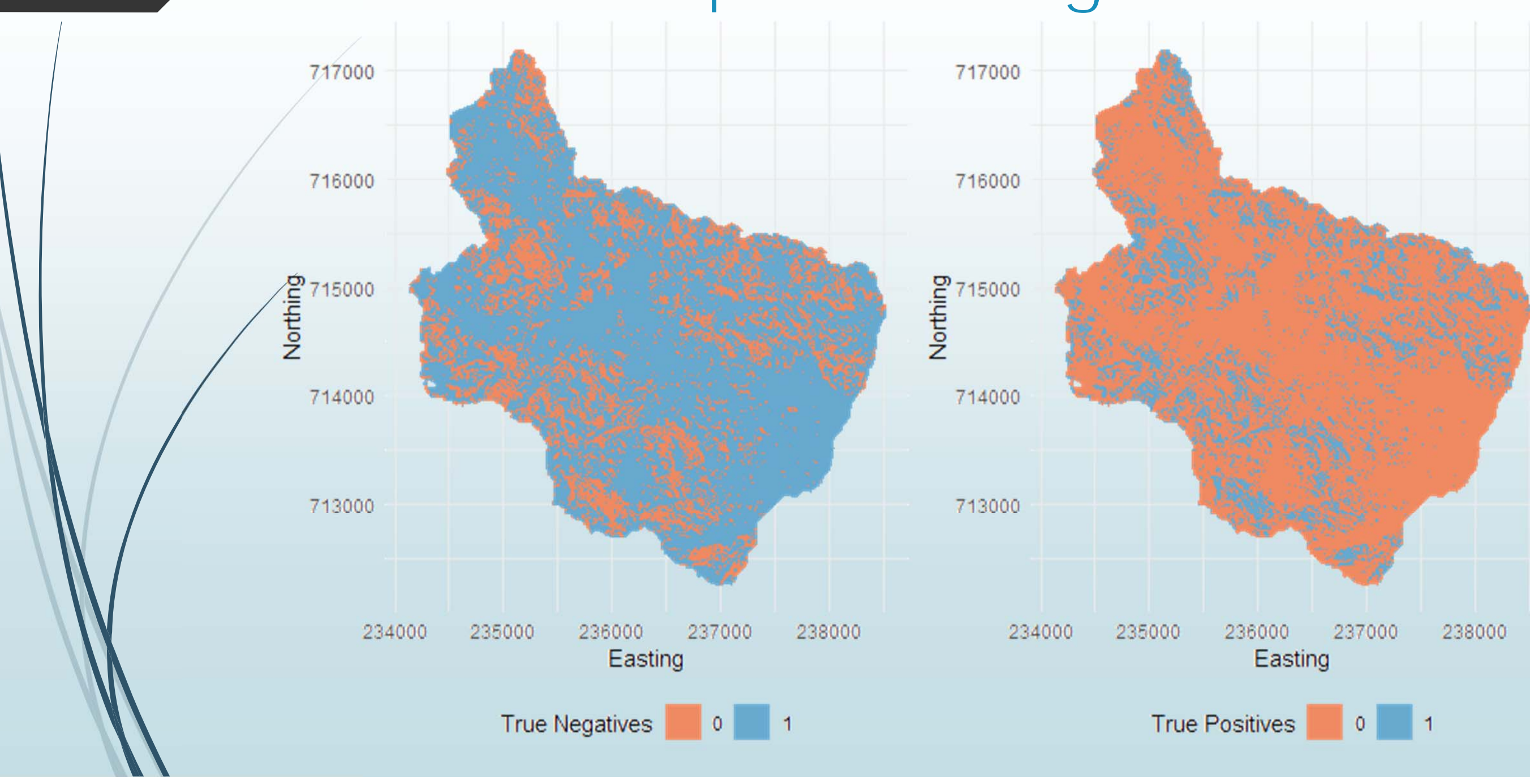

True Negatives

True Positives 


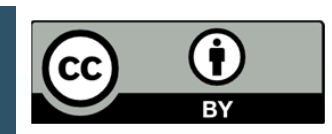

\section{Results: most important va ria bles (1)}
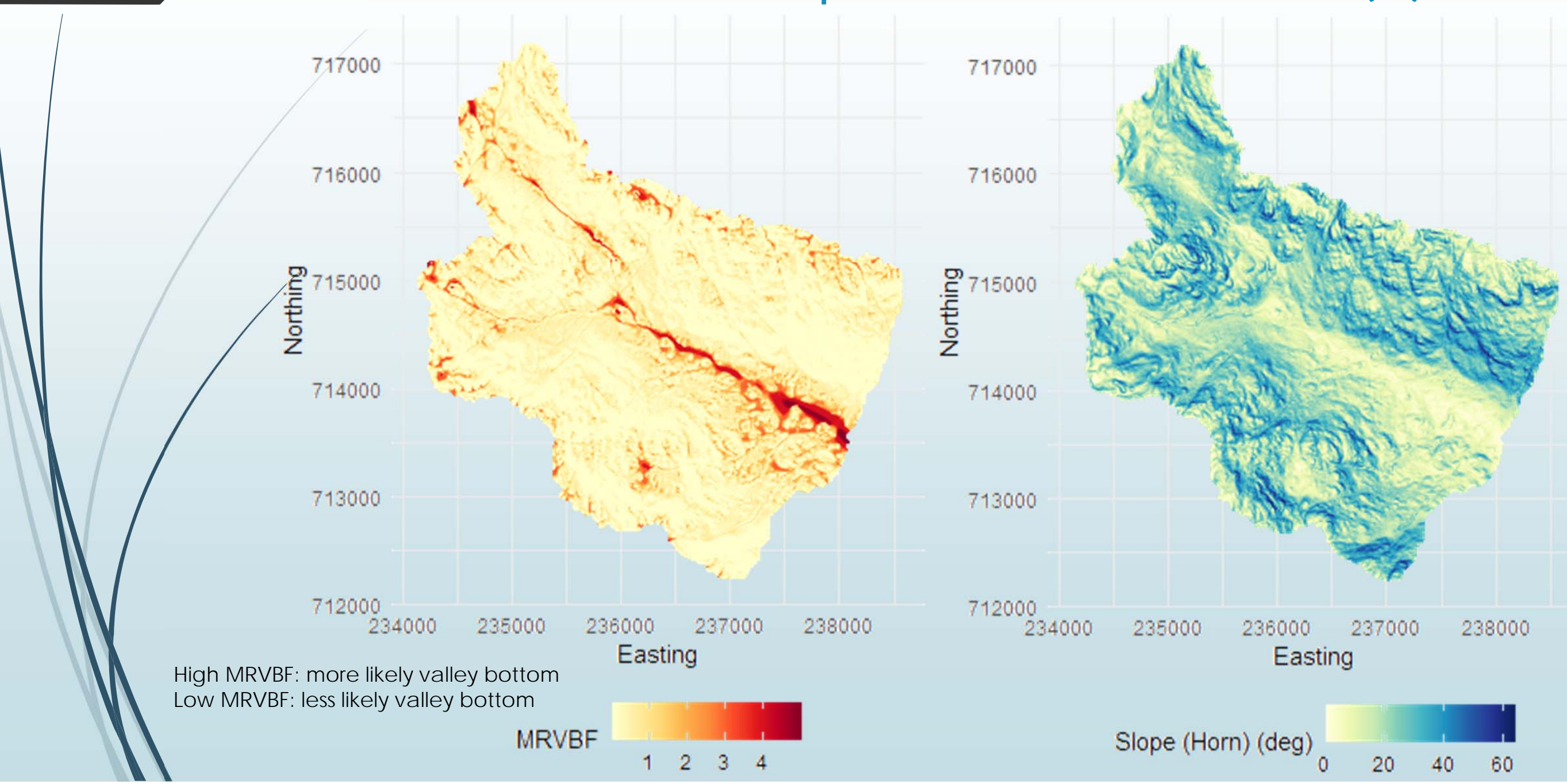

High MRVBF: more likely valley bottom

MRVBF 


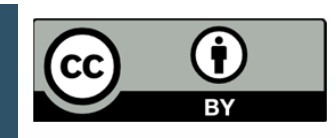

\section{Results: most importa nt va ria bles (2)}
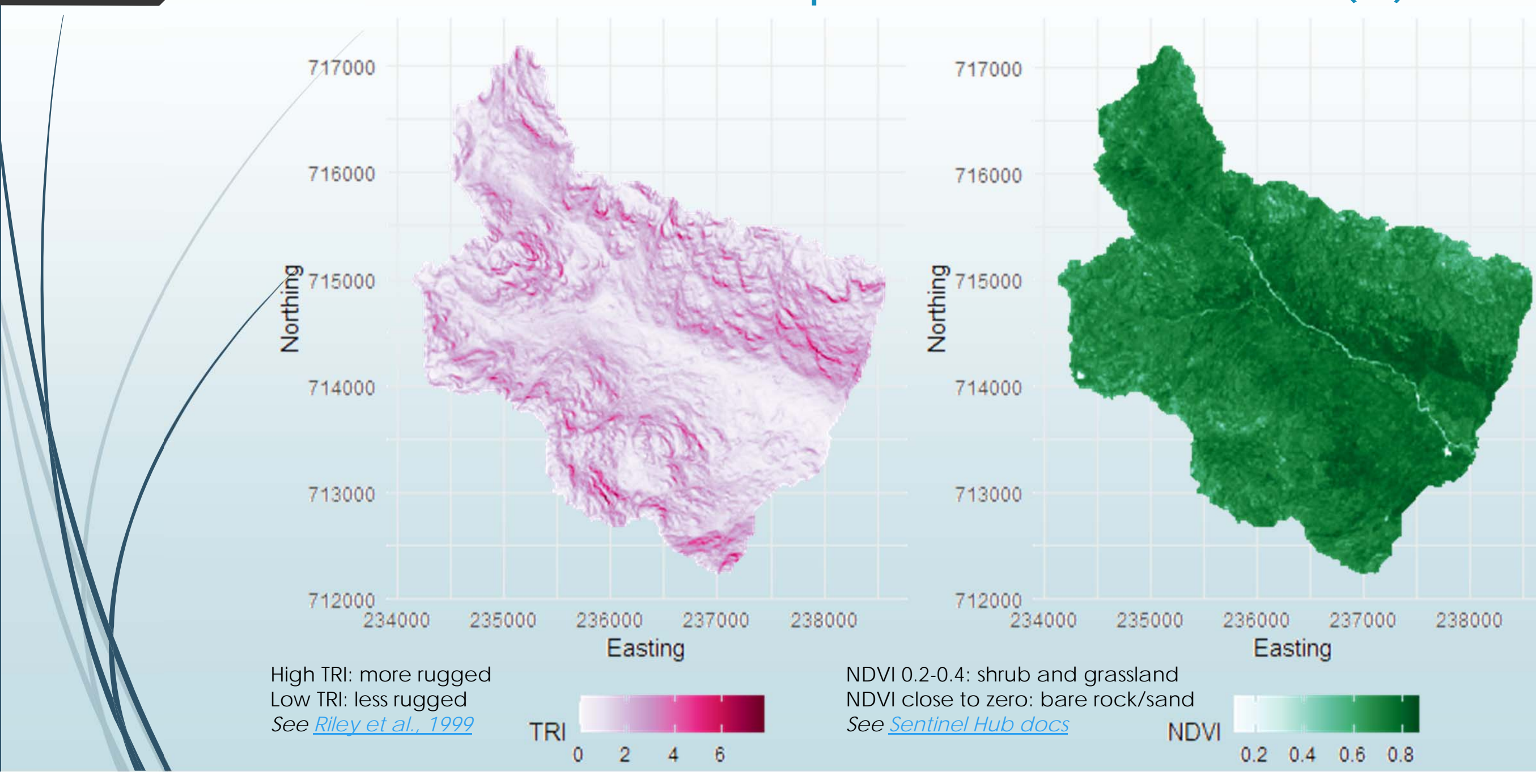

High TRI: more rugged

Low TRI: less rugged

See Riley et al., 1999

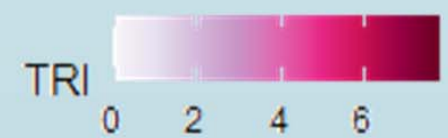

NDVI close to zero: bare rock/sand

See Sentinel Hub docs NDVI 


\section{(c) (1)}

\section{Next steps}

\section{For the montane and valley} domain...

- Application of the model to different a reas within the same doma in

- Hyperparameter tuning of the model

- Consideration of different scales of terrain derivatives included

a Analysis of true/false positives/negatives rela tive to va riable spatial distributions

- Consideration of the variability in the rock mapping training data development considering different mappers

\section{For other domains...}

- Collection of training data for c atchments in different doma ins

- Development of new models for each of these different domains 


\section{References}

- Benn, D.I. and Evans, D.J.A. 1998. Glaciers and Glaciation. Amold, London.

- Booth, S., Meritt, J and Rose, J . 2015. Quatemary Provinc es and Doma ins - a qua ntitative and qualita tive description of British landscape types. Proceedings of the Geologists' Association, 126 (2), pp 163-187. https://doi.org/10.1016/j.pgeola.2014.11.002.

- Eyles, N. 1983. Glacial Geology: An Introduction for Engineers and Earth Scientists. Pergamon Press, Oxford.

- Riley S.J., DeG loria, S.D. and Elliot, R. 1999. A Terrain Ruggedness Index That Quantifies Topographic Heterogeneity. IntemationalJ oumal of Sciences, 5(1-4), pp23-27.

- Scarpone, C., Schmidt, M. G., Bulmer, C. E. and Knudby, A. 2017. Semiautomated classific ation of exposed bedrock cover in British Columbia's Southem Mountains using a Random Forest approach. Geomorphology, 285. pp214-224. http://dx.doi.org/10.1016/j.geomorph.2017.02.013. 